\title{
Associations of socio-demographic factors with adiposity among immigrants in Norway: a secondary data analysis
}

\author{
Samera Azeem Qureshi ${ }^{1 *}$ D, Melanie Straiton ${ }^{2}$ and Abdi A. Gele ${ }^{1}$
}

\begin{abstract}
Background: Obesity is becoming an important public health challenge, especially among immigrants coming from low and middle income to high-income countries. In this study we examined the relationship between overweight/obesity and various socio-demographic indicators among different immigrant groups in Norway.

Methods: We used data from the Living Conditions Survey among Immigrants 2016, conducted by Statistics Norway. Our study sample included 4194 immigrants from 12 different countries. Participants were asked about a number of topics including health, weight, height, demographic factors, length of residence and employment. We ran logistic regression analysis to determine the odds ratio (OR) of the associations between socio-demographic factors with adiposity among immigrants.
\end{abstract}

Results: Approximately 53\% of the sample was overweight/obese. There was a significant difference in overweight/ obesity by gender, age, country of origin and marital status. Overall immigrant men were almost $52 \%$ more likely to be overweight/obese than women. Women from Somalia had the highest odds (13.1; Cl: 7.4-23.1) of being overweight/obese, followed by Iraq (8.6; Cl: 4.9-14.9), Pakistan (7.5; Cl: 4.2-13.4), Kosovo (7.0; Cl: 4.1-12.1), and Turkey (6.8; Cl: 4.0-11.6) as compared to the women from Vietnam (reference). Whereas men from Turkey had the highest odds (5.2; Cl: (3.2-8.3)) of being overweight/obese, followed by Poland (4.2; Cl: 2.7-6.1), Bosnia (4.1; Cl: (2.66.5) and Kosovo (3.9; $\mathrm{Cl}: 2.5-6.1)$. The odds for obesity increased with age and odds were highest in the eldest group 45-66 years (4.3; Cl: 3.2-5.8) as compared to reference group16-24 years. The odds of being overweight/ obese was higher among married (1.6; Cl: 1.3-1.9) and divorced/separated/widowed (1.5; Cl: 1.1-2.0) as compared to singles. Education, employment status, physical activity and length of residence were not associated with the odds of being overweight/obese.

Conclusion: The findings of this study call attention to the importance of a greater understanding of the processes leading to obesity among certain immigrant groups in Norway. Moreover, there is a need for culturally adapted prevention strategies targeting immigrant men and women with high rates of overweight/obesity.

Keywords: Obesity, Immigrants, Public health, Norway, Odds ratio

\footnotetext{
* Correspondence: samera.qureshi@fhi.no

'Unit for Migration \& Health, Norwegian Institute of Public Health (NIPH),

P.O.Box 222, 0213 Oslo, Skøyen, Norway

Full list of author information is available at the end of the article
}

\section{$\triangle B M C$}

C C The Author(s). 2020 Open Access This article is licensed under a Creative Commons Attribution 4.0 International License, which permits use, sharing, adaptation, distribution and reproduction in any medium or format, as long as you give appropriate credit to the original author(s) and the source, provide a link to the Creative Commons licence, and indicate if changes were made. The images or other third party material in this article are included in the article's Creative Commons licence, unless indicated otherwise in a credit line to the material. If material is not included in the article's Creative Commons licence and your intended use is not permitted by statutory regulation or exceeds the permitted use, you will need to obtain permission directly from the copyright holder. To view a copy of this licence, visit http://creativecommons.org/licenses/by/4.0/ The Creative Commons Public Domain Dedication waiver (http://creativecommons.org/publicdomain/zero/1.0/) applies to the data made available in this article, unless otherwise stated in a credit line to the data. 


\section{Background}

Obesity is a reversible predisposing factor and a serious threat for the development of chronic diseases such as cardiovascular disease (CVD), type 2 diabetes, cancer, hypertension and coronary heart disease [1-3]. Obesity is also linked to higher mortality and higher risk of mental health problems, musculoskeletal problems, and a general lower quality of life [2]. Despite being a leading cause of death, approximately 2 billion individuals are affected by obesity worldwide [4], and the number of overweight/obese individuals continue to grow with many finding it difficult to maintain a 'normal' weight in today's largely obesogenic environment.

Prevalence of obesity is on the rise not only in highincome countries (HICs) but also in low- and middleincome countries (LMIC) [5-10]. As compared to 10 or 20 years ago, a much larger part of European populations are immigrants [4]. From 2000 to 2015, globally international migration increased by $41 \%$, with over 244 million people now living in a country other than where they were born [11]. The population of immigrants in Europe, born outside the EU-states increased from 2,48 million in 2010 to 3,22 million in 2018 [12].

Findings from previous studies suggest that immigrants from LMIC have much healthier body weights and diet upon arrival to HICs, than the local community $[13,14]$. However, some immigrant groups are at a higher risk of becoming overweight/obese [15-19]. Migration from LMIC to HIC profoundly affects lifestyle, in particular dietary habits, nutrient intake, and physical activity as a result of both westernization and urbanization [20-24]. Immigrants adapt to the more refined high energy density diet of the HIC, rich in fat and sugars. This combined with physical inactivity, interaction between genetic susceptibility and environmental factors (i.e. diet, smoking and exercise), psychological stress, immune-inflammatory changes, inequalities in access to and lower quality of health care, inappropriate management and the under detection of morbidities [23-25] all contribute to increase in weight.

Another important contributing factor being that healthy foods such as vegetables and fresh fruits or organic food is much more expensive than high energy density food, such as sweets or fats [26-28]. It is established that socio-economic factors play a considerable role in food choices [29], leading to an unhealthy weight gain and a greater obesity risk $10-15$ years after migration [13]. In addition to lifestyle factors, socio-demographic factors such as sex, age, education, income level, marital status and physical activity affect body composition [30-32]. Increasing age, low income, low education and sedentary lifestyle are related to high BMI [30, 33]. Furthermore, published literature identifies global migration phenomenon as a social determinant of health [34].
According to a report by the Norwegian Institute of Public Health (NIPH), the prevalence of obesity among middle-aged (40-45 years) men was $25 \%$ and $20 \%$ in women in Norway [35]. Immigrants make up almost $18 \%(979,254)$ of Norway's total population [36] however, few studies have examined obesity among immigrants in Norway [21, 37, 38], and to our knowledge no prior study has looked at the relationship between overweight/obesity and socio-demographic factors among different immigrant groups. In this study, we aim to fill this research gap by assessing the relationship between overweight/obesity and various sociodemographic indicators such as age, gender, education, marital status etc. among different immigrant groups in Norway.

\section{Methods}

\section{Data source}

This study is based on data from a cross-sectional population-based survey conducted by Statistics Norway; "Living Conditions Survey among Immigrants 2016 (LKI_2016)” in 2015/16 [36, 39]. The survey covered a number of topics including demographic factors, family, housing, employment and the working environment, social contact, discrimination, Norwegian language proficiency, attitudes and values and health. Many of the questions are based on those from the European Social Survey [40].

The participation criteria for LKI_2016 was being an immigrant (Immigrants were defined as individuals born abroad with two foreign-born parents and four foreignborn grandparents) aged 16 years and above, living in Norway with a minimum of 2 years' residence by 1 st October 2015, and originally from Poland, Bosnia and Herzegovina, Kosovo, Turkey, Iraq, Iran, Afghanistan, Pakistan, Sri Lanka, Vietnam, Eritrea and Somalia. The number of participants above retirement age (67 years) were very few, so we include only those up to age 66 years in our analyses. At the time of data collection, there were 214,000 immigrants from these countries living in Norway, making up almost one third of all immigrants [39].

From the randomly selected immigrants, groups of 500-900 individuals were sent an invitation letter with a brief description of the intent of the project, and address to respond (email or telephone) in case they were willing to participate (consent), and a brochure explaining the project every other week [41]. In recognition of their participation all participants were offered a gift card worth 300 kroners (30 Euros). If the participants were willing to participate in the survey, they responded either by email or phone and indicated the channel they would prefer for the interview.

The data in LKI_2016 was collected by computerassisted telephone, or face-to-face interviews at a place 
of the participants' choice. Data collection was conducted between November 2015 and July 2016. Eighteen percent of the interviews were conducted as personal interviews, and $82 \%$ were over the telephone. Interviews were available in each of the 12 countries main language(s) in addition to English. More detailed description of sampling and data collection is available in the report from Statistics Norway [39].

\section{Sample}

A total of 8156 immigrants, aged 16-74 years were randomly selected from the population register on 1.10.2015. Of this, 4435 immigrants (1971 women and 2368 men) from aforementioned 12 countries participated in the study, a response rate of $54.4 \%$. However, less than $2 \%$ $(N=85)$ of the participants were over 67 years, too few when broken down by gender and country background. They were therefore removed from the sample. In addition, 156 participants did not report either their height or weight and as a result their Body Mass Index (BMI) could not be calculated, and as BMI is our main response variable we removed these participants from the sample, leaving 4194 participants (men $N=2334$ and women $N=1860$ ) in the analyses.

\section{Ethics}

This dataset was collected by Statistics Norway and issued by the Norwegian Centre for Research Data. Ethical approval or consent from participants was not required for this study because the dataset was anonymized. We conducted the analyses in accordance with the Norwegian Centre for Research Data's data protection regulations.

\section{Variables}

BMI: respondents were asked to report their weight (without clothes and shoes) in kilograms and height (without shoes) in metres. If the respondent was pregnant she was asked to report her weight before pregnancy. According to the WHO definition, BMI was divided into four categories underweight $(<18.5)$, normal (18.5-24.9), over-weight (25.0-29.9) and obese $(\geq 30.0)$ [42]. For the analysis, we collapsed the categories underweight and normal weight into one category because of few numbers in the underweight category. We further modified the BMI variable into a dichotomous variable "not overweight/obese" (BMI <25) and "overweight/ obese" (merging over-weight and obese categories) $\mathrm{BMI} \geq 25$. The following variables were used in the analyses gender, age-groups, marital and employment status, time of residence, self-reported diabetes and physical activity. They were categorized as; gender: men (0), women (1). Age-groups; 16-24 years, 25-44 years, 45-66 years. Country of origin; Poland, Turkey, Bosnia-Herzegovina, Kosovo, Eritrea, Somalia, Afghanistan, Sri-Lanka, Iraq,
Iran, Pakistan and Vietnam. We used Vietnam as the reference category. Employment Status; employed/ not employed. Marital status; Cohabitant/Married, Single, Widowed/Divorced/Separated. Education; < 10 years, Elementary school (10 years), High school (13 years), University level. Length of residence; 'less than 15 years' and 'more than 15 years'. Diabetes; Yes/No. Physical Activity; was defined as any activity (walk briskly, sports, swimming) for $30 \mathrm{~min}$ or longer. It was categorized as 'never', 'less than once/week', 'once/week'.

\section{Statistical analysis}

We used a combination of chi-square and t-tests to see the differences between the two groups (Not overweight/obese, overweight/obese). We ran several logistic regression [43] analyses to assess the association between BMI and various socio-demographic indicators among immigrants while controlling for the covariates [43]. We present the crude analysis (model 1), and model 2 with adjustments for gender, age group, country of origin, marital status, education, physical activity, residence time, self-reported diabetes and employment. We also ran regression analyses separately for men and women. We report significance levels, $p<0.05$ significant, $p<0.001$ highly significant and 95\% confidence intervals. We used statistical software STATA version 15 for all the analysis.

\section{Results}

Our study sample included 4194 immigrants from 12 different countries. Approximately $53 \%$ of the sample (both men and women) was overweight/obese. Table 1 presents the distribution of participant characteristics by overweight/obesity and associations between participant characteristics and overweight/obesity. There was a significant difference in overweight/obesity by gender. More men (60\%) were overweight/obese as compared to women (44\%). Participants aged between 45 and 66 years comprised only (33\%) of the sample but had the highest proportion (68\%) of overweight/obese individuals. The highest proportion of overweight/obese individuals (67\%) were from Turkey, followed by Poland (63\%) and the lowest $(27 \%)$ were from Vietnam.

Almost three-quarters of married individuals were overweight/obese $(74 \%)$ and $81 \%$ of self-reported diabetic participants were overweight/obese compared to $51 \%$ of non-diabetics. There was little variation in overweight/obesity by education and physical activity.

In both the crude and adjusted models (Table 1), men had twice the odds of being overweight/obese as compared to women. The odds of being overweight/obese increased with age. Immigrants from Turkey had 5.9 times the odds (CI; 4.2-8.4) of being overweight/obese as compared to those from Vietnam, followed by 
Table 1 Distribution of participant characteristics by overweight/obesity and associations (odds ratio (OR) and 95\% confidence intervals (95\% Cl) between participant characteristics and overweight/obesity, $n=4194$ immigrants in the 2016 Living Conditions Survey in Norway

\begin{tabular}{|c|c|c|c|c|}
\hline & Total n (\%) & $\begin{array}{l}\text { Overweight/obese } \\
B M I \geq 25.0 \mathrm{~kg} / \mathrm{m}^{2}\end{array}$ & $\begin{array}{l}\text { Model } 1 \text { (crude) } \\
\text { OR }(95 \% \mathrm{Cl})\end{array}$ & $\begin{array}{l}\text { Model } 2 \text { (adjusted) } \\
\text { OR }(95 \% \mathrm{Cl})\end{array}$ \\
\hline & 4194 & 2221 (53.0) & & \\
\hline \multicolumn{5}{|l|}{ Gender } \\
\hline Men & 2334 (55.7) & 1394 (59.7) & 1 & 1 \\
\hline Women & $1860(44,3)$ & $827(44.5)$ & $0.5(0.5-0.6)$ & $0.5(0.4-0.6)$ \\
\hline \multicolumn{5}{|l|}{ Age-groups } \\
\hline $16-24$ & $563(13.4)$ & $153(27.2)$ & 1 & 1 \\
\hline $25-44$ & $2251(53.7)$ & $1128(50.1)$ & $2.7(2.2-3.3)$ & $2.4(1.9-3.1)$ \\
\hline $45-66$ & 1380 (32.9) & $940(68.1)$ & $5.7(4.6-7.1)$ & $4.3(3.2-5.8)$ \\
\hline \multicolumn{5}{|l|}{ Country of origin } \\
\hline Vietnam & $329(7.8)$ & $90(27.4)$ & 1 & 1 \\
\hline Turkey & $341(8.1)$ & $228(66.7)$ & $5.4(3.8-7.5)$ & $5.9(4.2-8.4)$ \\
\hline Kosovo & $362(8.6)$ & $227(62.7)$ & $4.5(3.2-6.2)$ & $5.9(4.2-8.3)$ \\
\hline Poland & 365 (8.7) & $229(62.7)$ & $4.5(3.2-6.2)$ & $5.6(4.0-8.1)$ \\
\hline Iraq & $340(8.1)$ & 201 (59.1) & $3.8(2.8-5.3)$ & $5.4(3.8-7.7)$ \\
\hline Pakistan & $292(6.9)$ & $192(65.8)$ & $5.1(3.6-7.2)$ & $5.0(3.5-7.2)$ \\
\hline Bosnia & $345(8.2)$ & $208(60.3)$ & $4.0(2.9-5.6)$ & $4.6(3.2-6.4)$ \\
\hline Somalia & $344(8.2)$ & $168(48.8)$ & $2.5(1.8-3.5)$ & $4.1(2.9-6.0)$ \\
\hline Afghanistan & $345(8.2)$ & $147(42.6)$ & $2.0(1.4-2.7)$ & $3.7(2.6-5.4)$ \\
\hline Iran & $381(9.1)$ & $196(51.4)$ & $2.8(2.0-3.8)$ & $3.4(2.4-4.8)$ \\
\hline Sri Lanka & $373(8.9)$ & $201(53.9)$ & $3.1(2.3-4.3)$ & $2.8(2.0-3.9)$ \\
\hline Eritrea & 377 (9.0) & 134 (35.5) & $1.5(1.1-2.0)$ & $2.1(1.5-3.0)$ \\
\hline \multicolumn{5}{|l|}{ Marital status } \\
\hline Single & $1017(24.2)$ & $352(16.0)$ & 1 & 1 \\
\hline Cohabitant/Married & 2792 (66.6) & $1650(74.3)$ & $2.7(2.3-3.2)$ & $1.6(1.3-1.9)$ \\
\hline Widowed/Divorced/Separated & $382(9.1)$ & $219(10.0)$ & $2.5(2.0-3.2)$ & $1.5(1.1-2.0)$ \\
\hline \multicolumn{5}{|l|}{ Education } \\
\hline$<10$ years & $812(19.4)$ & $436(53.6)$ & 1 & 1 \\
\hline 10 years & $1443(34.4)$ & $724(50.2)$ & $0.9(0.7-1.0)$ & $1.0(0.9-1.3)$ \\
\hline 13 years & $974(23.2)$ & $557(57.2)$ & $1.1(1.0-1.4)$ & $1.0(0.8-1.3)$ \\
\hline University & $975(23.2)$ & $504(51.7)$ & $0.9(0.8-1.1)$ & $0.8(0.7-1.0)$ \\
\hline \multicolumn{5}{|l|}{ Length of residence } \\
\hline$<=15$ Years & $2569(61.2)$ & $1263(49.1)$ & 1 & 1 \\
\hline$>15$ years & $1625(38.8)$ & $958(59.0)$ & $1.5(1.3-1.7)$ & $1.1(0.9-1.4)$ \\
\hline \multicolumn{5}{|l|}{ Self-reported diabetes } \\
\hline No & 3964 (94.5) & $2042(51.5)$ & 1 & 1 \\
\hline Yes & $222(5.5)$ & $179(81.0)$ & $3.9(2.8-5.5)$ & $2.4(1.7-3.4)$ \\
\hline \multicolumn{5}{|l|}{ Physical Activity/week } \\
\hline Never & $794(19.0)$ & $450(57.0)$ & 1 & 1 \\
\hline$<$ Once & $939(22.4)$ & $511(54.4)$ & $0.9(0.7-1.1)$ & $1.0(0.8-1.2)$ \\
\hline Once or more & $2458(58.6)$ & $1258(51.2)$ & $0.8(0.7-0.9)$ & $0.9(0.8-1.1)$ \\
\hline \multicolumn{5}{|l|}{ Employment Status } \\
\hline Employed & $2717(64.8)$ & $1417(52.1)$ & 1 & 1 \\
\hline Not employed & $1469(35.2)$ & $801(54.2)$ & $1.1(1.0-1.2)$ & $1.2(1.1-1.4)$ \\
\hline
\end{tabular}


immigrants from Kosovo, Poland, Iraq and Pakistan. Those who were married/cohabiting or divorced/separated or widowed had higher odds of being overweight/ obese as compared to never married participants. Similarly, those who were unemployed were $10 \%$ more likely to be overweight/obese as compared to employed immigrants. Participants with self-reported diabetes were 2.4 times more likely to be overweight/obese compared to those without diabetes. We did not find any significant relationship between overweight/obesity and education, physical activity or length of residence in Norway.

We also ran regression analyses separately for men and women, and present the results of only the adjusted analyses in Table 2. The odds for overweight/ obesity were greatest in Somali, Iraqi and Pakistani women compared with Vietnamese women who were the least overweight/obese. Whereas odds for overweight/obesity were greatest in men from Turkey, Poland, Bosnia and Kosovo. Age was an important factor for both men and women with the oldest group (45-66 years) having the highest odds of overweight/ obesity as compared to the youngest (16-24 years). While physical activity was not related to overweight/ obesity for men, women exercising at least once a week had a $24 \%$ lower chance of being overweight/obese. The odds for being overweight/obese were 5.1 (CI; 2.610.0) in self-reported diabetic women as compared to non-diabetic women. Women who were not employed had a $31 \%$ higher chance of being overweight/obese as compared to women who were employed.

\section{Discussion}

This study assessed the relationship between overweight/obesity and socio-demographic factors among immigrants in Norway. The main socio-demographic factors identified were age, gender, country of origin and marital status. Having self-reported diabetes increased the odds of being overweight/obese. However, since the dataset is cross-sectional, we cannot establish whether overweight/obesity was due to self-reported diabetes or vice versa. We did not find any association between education, employment status, being physically active and overweight/obesity.

Age is a strong determinant of overweight/obesity in our study, which is in line with previous research $[21,44,45]$. The results also show higher overweight/ obesity among immigrant men as compared to women. This higher obesity among men, is in line with the obesity trend in the general population in Norway [46, 47]. The study shows that Turkish, Polish, Bosnian, and Kosovan men have the highest odds of being overweight/obese even after adjustment for age, marital status, physical activity and employment status. This finding is similar to that of another study done in Australia, where they reported evidences of ethnic difference in overweight/obesity among males from North Africa/ Middle East [48]. In addition, data from all these countries indicate a rise in overweight/ obesity among men $[49,50]$. Furthermore, all these countries are located in Europe and the percentage of overweight/obese individuals among men has increased four times in Europe over the last few years [50, 51]. A literature review published in 2012, stated that in developed countries, more men are overweight than women. This may be the result of socio-cultural dynamics, gender differences in terms of consumption of food, and acculturation through complex sociocultural pathways [52].

Our study also showed that the country of origin had a significant association with the odds of being overweight/obese. In Norway, immigrants come from over 200 cultural settings and prevention of overweight/obesity among the highly diverse immigrant communities is a challenge. This challenge partially stems from the fact that many immigrant communities have different concepts of health and health care than mainstream societies in the receiving country [53]. For example, a slim body is associated with poverty and ill health in many African cultures, while physical activity is perceived as something that is integrated into everyday lives; thus the promotion of leisure time physical activity such as joining a fitness class or going for a long walk or jogging is not considered as useful or necessary [54]. In some communities, activities involving sweating and deep breathing are associated with negativity, whereas sitting and resting are associated with affluence. This cultural practice might have affected the results of our study and thus we did not find an overall association between physical activity and overweight/obesity in our sample.

However, when we stratified our analyses by gender we observed an association (OR: 0.7: CI; 0.6-0.9) of physical activity with the odds of being overweight/ obese, among women who engaged in physical activity once or more per week. This may be a chance (random error) finding. A fundamental problem in making a causal interpretation of associations from observational data is the possibility that such associations are due to confounding. Although we did adjust our estimates for confounders, we cannot exclude the possibility of residual confounding, as we had to rely on the information provided by the participants. Thus we cannot rule out the possibility of over reporting and possible misclassification of the physical activity variable. Furthermore, lack of data on dietary intake in our sample precludes us from drawing any conclusion based on the association between diet and physical activity. However, it is well-known that immigrants may have an increasingly unhealthy diet after migration to HIC, but their diet is generally healthier 
Table 2 Associations (odds ratio (OR) and 95\% confidence intervals (95\% Cl) between participant characteristics and overweight/ obesity stratified by gender

\begin{tabular}{|c|c|c|c|}
\hline & Men & & Women \\
\hline & Odds Ratio $(95 \% \mathrm{Cl})$ & & Odds Ratio (95\% Cl) \\
\hline Age-groups & & Age-groups & \\
\hline $16-24$ & 1 & $16-24$ & 1 \\
\hline $25-44$ & $2.9(2.3-3.8)$ & $25-44$ & $2.9(1.9-4.5)$ \\
\hline $45-66$ & $5.2(3.3-6.8)$ & $45-66$ & $6.4(4.0-10.4)$ \\
\hline Country of origin & & Country of origin & \\
\hline Vietnam & 1 & Vietnam & 1 \\
\hline Turkey & $5.2(3.2-8.3)$ & Somalia & $13.1(7.4-23.1)$ \\
\hline Poland & $4.2(2.7-6.1)$ & Iraq & $8.6(4.9-14.9)$ \\
\hline Bosnia & $4.1(2.6-6.5)$ & Pakistan & $7.5(4.2-13.4)$ \\
\hline Kosovo & $3.9(2.5-6.1)$ & Kosovo & $7.0(4.1-12.1)$ \\
\hline Pakistan & $3.5(2.2-5.5)$ & Turkey & $6.8(4.0-11.6)$ \\
\hline Iraq & $2.7(1.7-4.2)$ & Poland & $5.7(3.2-10.2)$ \\
\hline Iran & $2.4(1.5-3.6)$ & Afghanistan & $5.5(3.0-10.1)$ \\
\hline Sri Lanka & $2.1(1.3-3.2)$ & Bosnia & $4.8(2.8-8.2)$ \\
\hline Afghanistan & $1.2(0.8-1.8)$ & Sri Lanka & $4.5(2.7-7.6)$ \\
\hline Somalia & $1.0(0.6-1.6)$ & Iran & $4.3(2.5-7.3)$ \\
\hline Eritrea & $0.9(0.6-1.4)$ & Eritrea & $3.8(2.2-6.5)$ \\
\hline Marital status & & Marital status & \\
\hline Single & 1 & Single & 1 \\
\hline Cohabitant/Married & $3.0(2.5-3.7)$ & Cohabitant/Married & $1.9(1.4-2.6)$ \\
\hline Widowed/Divorced/Separated & $2.4(1.7-3.5)$ & Widowed/Divorced/Separated & $1.9(1.3-2.9)$ \\
\hline Education & & Education & \\
\hline$<10$ years & 1 & $<10$ years & 1 \\
\hline 10 years & $0.9(0.7-1.7)$ & 10 years & $1.1(0.8-1.5)$ \\
\hline 13 years & $1.4(1.1-1.8)$ & 13 years & $1.1(0.76-1.5)$ \\
\hline University & $1.3(1.0-1.7)$ & University & $0.7(0.5-1.0)$ \\
\hline Length of residence & & Length of residence & \\
\hline$<=15$ Years & 1 & $<=15$ Years & 1 \\
\hline$>15$ years & $1.2(0.9-1.5)$ & $>15$ years & $1.1(0.9-1.5)$ \\
\hline Self-reported diabetes & & Self-reported diabetes & \\
\hline No & 1 & No & 1 \\
\hline yes & $2.4(1.6-3.6)$ & yes & $5.1(2.6-10.0)$ \\
\hline Physical Activity/week & & Physical Activity/week & \\
\hline Never & 1 & Never & 1 \\
\hline$<$ Once & $1.1(0.9-1.5)$ & $<$ Once & $1.0(0.7-1.3)$ \\
\hline Once or more & $1.2(0.9-1.5)$ & Once or more & $0.8(0.6-0.9)$ \\
\hline Employment Status & & Employment Status & \\
\hline Employed & 1 & Employed & 1 \\
\hline Not employed & $1.1(0.9-1.4)$ & Not employed & $1.3(1.0-1.6)$ \\
\hline
\end{tabular}

than native populations, so this is unlikely to be a major contributor to increased obesity risk [13]. Our results demonstrate an association between physical activity and overweight/obesity among women but not for men, however we are unable to support this finding from published studies due to paucity of relevant literature. 
We did not find an association between the length of residence and being overweight/obese. Although, published studies show that with the passage of time, immigrants gain more weight $[15,55-57]$. Higher rates of obesity among some groups of immigrants in Norway may be explained by immigrants' adaptation to an unhealthy lifestyle. Evidence presented across multiple studies indicate an association between acculturation, measured by duration of stay in the receiving country and obesity [20, 57, 58]. Gele and Mbalilaki, who estimated the prevalence of obesity among African immigrants in Norway, found that the obesity pattern increased with the duration of stay in Norway, as evidenced by a higher BMI rate beginning after 5 years [21]. As stated before, immigrant health deteriorates and $\mathrm{BMI}$ increases as time since migration increases, and this does not become evident before $10-15$ years $[20,59,60]$, so the cut-off 15 years residence time in our study seems reasonable. However, it is difficult to determine if this increase in BMI is due to unhealthy acculturation or it would have simply increased even if immigrants remained in their country of origin [60].

Our results showed that Somali women had the highest likelihood of being overweight/obese. According to the WHO statistics (2008), obesity is rare in Somalia; approximately $3.1 \%$ of women and $6.4 \%$ of men were overweight/obese in 2008. Similarly, Somalia has the lowest prevalence of self-reported diabetes in Arab League countries [21]. Nevertheless, prior studies on obesity among Somali women have warned on increasing obesity among them with increased years of living in Norway [21, 61]. Research shows that the largest proportions of modifiable risk for self-reported diabetes among Somali women were contributed by high BMI and high waist circumference, which coincides with high prevalence of sedentary lifestyle [61]. Increased obesity among Somali women may be due to the limited access to a tailored physical exercise structure and, most importantly, a lack of proper health information to help them acquire adequate physical exercise [62].

A prior study highlighted the challenges that Somali women face in becoming physically active, which include time pressure, a lack of financial affordability for training facilities, and an absence of a tailored physical activity environment. Next to Somali women, women from Pakistan, Iraq, Turkey and Kosovo also have high odds of being overweight/obese. The overweight/obesity among women from Somalia, Pakistan and Iraq concords with global inactivity prevalence. In Eastern Mediterranean region, Somalia, Pakistan and Iraq, had the highest rates of inactivity among WHO regions, approaching $50 \%$ of women and $40 \%$ of men [37].

However, it would not be justifiable just to label physical inactivity as the lone cause of overweight/obesity. It is known that numerous factors influence body weight. Some of these factors such as dietary intake, physical activity, social factors can be individually controlled, whereas factors like developmental determinants, genetic makeup, gender, and age are out of individual control [63]. In case of overweight/obesity among Somali women, a probable explanation could be that in addition to their traumatic experiences in decades long civil war, they face a number of challenges, such as language barriers, discrimination, poor understanding of country's health system, and religious differences when adapting to their new country. This in turn leads to, an increase in sedentary behavior, coupled with a drastic change in diet and ultimately leading to cardiovascular risk, overweight, and diabetes [64].

Another important factor worth mentioning with regards to increased levels of overweight/obesity is low level of health literacy among many groups of immigrants [65]. A previous study reported low levels of health literacy among Somali women and $71 \%$ of them lacked the ability to obtain, understand and act upon health information and services, and to make appropriate health decisions [66]. Similarly, another study from Sweden reported, health literacy to be just $60 \%$, and factors such as being born in Somalia were associated with an increased risk of having an inadequate health literacy [67]. Therefore, having inadequate health literacy may also be responsible for the unhealthy behavior among immigrants.

Our study has some major limitations. An important limitation is its cross-sectional design, hence making it difficult to establish the causes. Moreover, most of the variables including weight and height were self-reported, with a distinct possibility of both under- or over-reporting. Research suggests that individuals have tendency to underreport their weight, and the size of the discrepancy between self-reported and actual weight increases with increasing body weight [68]. This may result in an underestimation of the number of individuals who are overweight/obese. However, the same is true for over-reporting as well. This points to the fact that we need more research to confirm the presence and direction of biases in weight-reporting among adults in different immigrant groups [69, 70]. Self-reported diabetes is another limitation of the study as up to $50 \%$ of individuals with diabetes in Norway are not aware of their diabetes status [71]. Therefore, self-reported diabetes is simply not a representation of adults with diabetes in Norway. Another limitation is that the low number of participants from the different immigrant communities might not be completely representative of immigrants as a whole in Norway, thus the findings may not be generalizable. The study also lacks detailed lifestyle questions. For instance, although dietary intake is a strong determinant 
of the body weight, data on neither caloric intake nor fruit and vegetable intake was available. Finally, collapsing the categories of overweight and obesity into one might have mitigated the estimates. However as previously mentioned, the dichotomous variable for overweight/obesity was per WHO cut offs $\left(\mathrm{BMI}>25 \mathrm{~kg} / \mathrm{m}^{2}\right.$ ) [72]. In addition, overweight/obesity as a combined category is clinically relevant due to the established health consequences of exceeding a body mass index of $25 \mathrm{~kg} / \mathrm{m}^{2}$ [73]. Furthermore, it is also a policy-relevant categorization reflecting international obesity reduction targets and indicators [72].

Despite these limitations, the study provides important information on overweight and obesity of different underresearched immigrant groups, in addition to highlighting specific groups that are at high risk of overweight/obesity and subsequent CVD. The high proportion of certain immigrant groups with obesity will generate considerable obesity-related costs owing to increased health care costs as well as productivity loss. This probable epidemic will also reduce the quality and duration of life in this population.

\section{Conclusions}

Our findings show that there is heterogeneity among different immigrant groups. Therefore to meet immigrant's preventive health needs, particularly obesity prevention, the host countries need a greater understanding of the health status, health behaviors, and risk factors prevalent in different ethnic groups.

In addition, our study suggests the need for culturally adapted prevention strategies targeting immigrant groups with high rates of obesity. Moreover, the findings of this study call attention to the importance of a greater understanding of the processes leading to obesity among different immigrant groups in Norway. Groups such as Somali, Pakistani, Kosovo and Iraqi women, and men from Turkey, Poland, Bosnia and Kosovo should be targeted.

\section{Abbreviations}

CVD: Cardiovascular disease; HICs: High-income countries; LMIC: Low- and middle-income countries; NIPH: Norwegian Institute of Public Health;

BMI: Body Mass Index; WHO: World Health Organization

\section{Acknowledgments}

We would like to thank all the participants of the study for their participation and help.

\section{Authors' contributions}

SAQ analyzed the data and drafted the manuscript. AG and MS contributed in editing of the manuscript. All authors were responsible for editing and improvement of the manuscript. All authors gave approval for the final version of the manuscript.

\section{Funding}

Not applicable.
Availability of data and materials

The data is available from NSD (Norwegian Centre for Research Data) upon request.

\section{Ethics approval and consent to participate}

The data is available from NSD (Norwegian Centre for Research Data) upon request. We signed a privacy contract before we started analysing the data. The survey was approved by the regional ethical committee and the participants gave written consent. The participants were free to withdraw at any time and their data was deleted immediately with no consequences.

\section{Consent for publication}

As our manuscript does not include any individual data or sensitive personal information, therefore consent for publication is "Not Applicable" in this case.

\section{Competing interests}

The authors declare no competing interest.

\section{Author details}

${ }^{1}$ Unit for Migration \& Health, Norwegian Institute of Public Health (NIPH), P.O.Box 222, 0213 Oslo, Skøyen, Norway. ${ }^{2}$ Department of Mental Health and Suicide, Norwegian Institute of Public Health (NIPH), P.O.Box 222, 0213 Oslo, Skøyen, Norway.

Received: 11 March 2020 Accepted: 14 May 2020

Published online: 24 May 2020

\section{References}

1. Dixon JB. The effect of obesity on health outcomes. Mol Cell Endocrinol. 2010;316(2):104-8.

2. WHO. WHO; 2018. Available from: https://www.who.int/news-room/factsheets/detail/obesity-and-overweight.

3. Hu F. Obesity epidemiology: Oxford University press; 2008

4. WHO. Overweight and obesity. Geneva: WHO; 2017.

5. Finucane MM, Stevens GA, Cowan MJ, Danaei G, Lin JK, Paciorek CJ, et al. National, regional, and global trends in body-mass index since 1980: systematic analysis of health examination surveys and epidemiological studies with 960 country-years and 9.1 million participants. Lancet (London, England). 2011;377(9765):557-67.

6. Popkin BM, Adair LS, Ng SW. Global nutrition transition and the pandemic of obesity in developing countries. Nutr Rev. 2012;70(1):3-21.

7. Stevens GA, Singh GM, Lu Y, Danaei G, Lin JK, Finucane MM, et al. National, regional, and global trends in adult overweight and obesity prevalences. Popul Health Metrics. 2012;10(1):22.

8. Wang $Y$, Beydoun MA. The obesity epidemic in the United States-gender, age, socioeconomic, racial/ethnic, and geographic characteristics: a systematic review and meta-regression analysis. Epidemiol Rev. 2007:29:6-28.

9. Rennie KL, Jebb SA. Prevalence of obesity in Great Britain. Obesity Rev. 2005; 6(1):11-2.

10. Ng M, Fleming T, Robinson M, Thomson B, Graetz N, Margono C, et al. Global, regional, and national prevalence of overweight and obesity in children and adults during 1980-2013: a systematic analysis for the Global Burden of Disease Study 2013. Lancet (London, England). 2014;384(9945): 766-81.

11. United Nations Department of Economic and Social Affairs Population Division. Trends in International Migration, 2015. Geneva: United Nations; 2015.

12. European Migration Network (EMN). Migrant population and immigration statistics in EU Member States Ireland 2018. Available from: https://emn.ie/ useful-statistics/migration-and-migrant-population-statistics-in-eu-28/.

13. Murphy M, Robertson W, Oyebode O. Obesity in international migrant populations. Curr Obes Rep. 2017;6(3):314-23.

14. Argeseanu Cunningham S, Ruben JD, Narayan KM. Health of foreign-born people in the United States: a review. Health Place. 2008;14(4):623-35.

15. da Costa LP, Dias SF, Martins MD. Association between length of residence and overweight among adult immigrants in Portugal: a nationwide crosssectional study. BMC Public Health. 2017:17(1):316.

16. Ujcic-Voortman JK, Schram MT. Jacobs-van der Bruggen MA, Verhoeff AP, Baan CA. Diabetes prevalence and risk factors among ethnic minorities. Eur J Pub Health. 2009;19(5):511-5. 
17. Holmboe-Ottesen G, Wandel M. Changes in dietary habits after migration and consequences for health: a focus on south Asians in Europe. Food Nutr Res. 2012;56:188-91.

18. Wandel M, Raberg M, Kumar B, Holmboe-Ottesen G. Changes in food habits after migration among south Asians settled in Oslo: the effect of demographic, socio-economic and integration factors. Appetite. 2008;50(23):376-85

19. Wandel M. Nutrition-related diseases and dietary change among third world immigrants in northern Europe. Nutr Health. 1993;9(2):117-33.

20. Argys $\mathrm{L}$. Consequences of the obesity epidemic for immigrants when migrants move to countries with high obesity rates, does assimilation lead to labor market penalties and higher health care costs? IZA world of labor; 2015.

21. Gele AA, Mbalilaki AJ. Overweight and obesity among African immigrants in Oslo. BMC Res Notes. 2013;6:119.

22. Neuhouser ML, Thompson B, Coronado GD, Solomon CC. Higher fat intake and lower fruit and vegetables intakes are associated with greater acculturation among Mexicans living in Washington state. J Am Diet Assoc. 2004;104(1):51-7.

23. Gilbert PA, Khokhar S. Changing dietary habits of ethnic groups in Europe and implications for health. Nutr Rev. 2008;66(4):203-15.

24. Misra A, Ganda OP. Migration and its impact on adiposity and type 2 diabetes. Nutrition (Burbank, Los Angeles County, Calif). 2007;23(9):696-708.

25. Landman J, Cruickshank JK. A review of ethnicity, health and nutritionrelated diseases in relation to migration in the United Kingdom. Public Health Nutr. 2001:4(2b):647-57.

26. Bernstein AM, Bloom DE, Rosner BA, Franz M, Willett WC. Relation of food cost to healthfulness of diet among US women. Am J Clin Nutr. 2010;92(5): 1197-203.

27. Rao M, Afshin A, Singh G, Mozaffarian D. Do healthier foods and diet patterns cost more than less healthy options? A systematic review and meta-analysis. BMJ Open. 2013;3(12):e004277.

28. McDermott AJ, Stephens MB. Cost of eating: whole foods versus convenience foods in a low-income model. Fam Med. 2010;42(4):280-4.

29. Sommer C, Sletner L, Jenum AK, Morkrid K, Andersen LF, Birkeland Kl, et al, Ethnic differences in maternal dietary patterns are largely explained by socio-economic score and integration score: a population-based study. Food Nutr Res. 2013;57:57-64.

30. Ohlsson B, Manjer J. Sociodemographic and lifestyle factors in relation to overweight defined by BMI and "Normal-weight obesity". J Obes. 2020;2020: 2070297.

31. Hjartaker A, Lund E. Relationship between dietary habits, age, lifestyle, and socio-economic status among adult Norwegian women. The Norwegian women and Cancer study. Eur J Clin Nutr. 1998;52(8):565-72.

32. Ruf $T$, Nagel G, Altenburg HP, Miller AB, Thorand B. Food and nutrient intake, anthropometric measurements and smoking according to alcohol consumption in the EPIC Heidelberg study. Ann Nutr Metabol. 2005;49(1):16-25.

33. Ahmed SH, Meyer HE, Kjollesdal MK, Madar AA. Prevalence and predictors of overweight and obesity among Somalis in Norway and Somaliland: a comparative study. J Obes. 2018;2018:4539171.

34. Rechel B, Mladovsky P, Ingleby D, Mackenbach JP, McKee M. Migration and health in an increasingly diverse Europe. Lancet (London, England). 2013; 381(9873):1235-45.

35. (NIPH) NloPH. Overweight and obesity in Norway. Public Health Report 2017. https://wwwfhino/en/op/hin/risk--protective-factors/overweight-andobesity-in-norway---/. 2017.

36. Statistics Norway. Immigrants and Norwegian-born to immigrant parents. 2020.

37. Raberg M, Kumar B, Holmboe-Ottesen G, Wandel M. Overweight and weight dissatisfaction related to socio-economic position, integration and dietary indicators among south Asian immigrants in Oslo. Public Health Nutr. 2010;13(5):695-703.

38. Kumar BN, Meyer HE, Wandel M, Dalen I, Holmboe-Ottesen G. Ethnic differences in obesity among immigrants from developing countries, in Oslo, Norway. Int J Obes (2005). 2006;30(4):684-90.

39. Vrålstad S, Wiggen K. Living conditions among imigrants in Norway 2016. Oslo-Kongsvinger: Statistics Norway; 2017. Report No.: 2017/13.

40. European Social Survey, ESS Methodology. Available from: https://www. europeansocialsurvey.org/methodology/ess_methodology/source_ questionnaire.
41. Holmøy A, Wiggen K. Levekår blant personer med innvandrerbakgrunn 2016. Dokumentasjonsrapport. (Notater 20/2017) Statistisk sentralbyrå. Oslo/ Kongsvinger: Statistics Norway (SSB); 2017.

42. WHO. 2019. Available from: http://www.euro.who.int/en/health-topics/ disease-prevention/nutrition/a-healthy-lifestyle/body-mass-index-bmi.

43. Altman DG. Practical statistics for medical research. London: Chapman \& Hall; 1991.

44. Jura M, Kozak LP. Obesity and related consequences to ageing. Age (Dordrecht, Netherlands). 2016;38(1):23.

45. Slawik M, Vidal-Puig AJ. Lipotoxicity, overnutrition and energy metabolism in aging. Ageing Res Rev. 2006;5(2):144-64.

46. Jacobsen BK, Aars NA. Changes in waist circumference and the prevalence of abdominal obesity during 1994-2008 - cross-sectional and longitudinal results from two surveys: the Tromso study. BMC Obes. 2016;3:41.

47. Midthjell K, Lee CM, Langhammer A, Krokstad S, Holmen TL, Hveem K, et al. Trends in overweight and obesity over 22 years in a large adult population: the HUNT study, Norway. Clin Obes. 2013;3(1-2):12-20.

48. Menigoz K, Nathan A, Turrell G. Ethnic differences in overweight and obesity and the influence of acculturation on immigrant bodyweight: evidence from a national sample of Australian adults. BMC Public Health. 2016;16:932.

49. Cihangir E. Prevalence of overweight and obesity in Turkey. IJC Metabol Endoc. 2015:8:38-41.

50. Krzysztoszek J, Laudanska-Krzeminska I, Bronikowski M. Assessment of epidemiological obesity among adults in EU countries. Ann Agric Environ Med. 2019;26(2):341-9.

51. Kontis V, Bennett JE, Mathers CD, Li G, Foreman K, Ezzati M. Future life expectancy in 35 industrialised countries: projections with a Bayesian model ensemble. Lancet (London, England). 2017;389(10076):1323-35.

52. Kanter R, Caballero B. Global gender disparities in obesity: a review. Adv Nutr (Bethesda, Md). 2012;3(4):491-8.

53. Issaka A, Lamaro G. A R. sociocultural factors and perceptions associated with type 2 diabetes among sub-Saharan African migrants in Melbourne, Victoria. Nutr Diet. 2015;73(1):28-35.

54. Persson G, Mahmud AJ, Hansson EE, Strandberg EL. Somali women's view of physical activity--a focus group study. BMC Womens Health. 2014;14:129.

55. McDonald JT, Kennedy S. Is migration to Canada associated with unhealthy weight gain? Overweight and obesity among Canada's immigrants. Soc Sci Med (1982). 2005;61(12):2469-81.

56. Ro A, Bostean G. Duration of U.S. stay and body mass index among Latino and Asian immigrants: A test of theoretical pathways. Soc Sci Med (1982). 2015:144:39-47.

57. Goel MS, McCarthy EP, Phillips RS, Wee CC. Obesity among US immigrant subgroups by duration of residence. Jama. 2004:292(23):2860-7.

58. Alidu L, Grunfeld EA. A systematic review of acculturation, obesity and health behaviours among migrants to high-income countries. Psychol Health. 2018;33(6):724-45.

59. Antecol $\mathrm{H}$, Bedard K. Unhealthy assimilation: why do immigrants converge to American health status levels? Demography. 2006;43(2):337-60.

60. Park J, Myers D, Kao D, Min S. Immigrant obesity and unhealthy assimilation: alternative estimates of convergence or divergence, 1995-2005. Soc Sci Med (1982). 2009;69(11):1625-33.

61. Gele AA, Pettersen KS, Kumar B, Torheim LE. Diabetes risk by length of residence among Somali women in Oslo area. J Diab Res. 2016;2016: 5423405.

62. Gele AA, Torheim LE, Pettersen KS, Kumar B. Beyond culture and language: access to diabetes preventive health services among Somali women in Norway. J Diab Res. 2015;2015:549795.

63. Institute of Medicine (US). Factors That Influence Body Weight. Weight Management: State of the Science and Opportunities for Military Programs. Washington (DC): National Academies Press (US); 2004

64. Guerin PB, Diiriye RO, Corrigan C, Guerin B. Physical activity programs for refugee Somali women: working out in a new country. Women Health. 2003;38(1):83-99.

65. WHO. Health literacy: The solid facts. Geneva: World Health Organization; 2013

66. Gele A, Pettersen K, Torheim L, Kumar B. Health literacy: the missing link in improving the health of Somali immigrant women in Oslo. BMC Public Health. 2016;16(1):1134. 
67. Wangdahl J, Lytsy P, Martensson L, Westerling R. Health literacy among refugees in Sweden - a cross-sectional study. BMC Public Health. 2014;14:1030.

68. Stommel M, Schoenborn CA. Accuracy and usefulness of BMI measures based on self-reported weight and height: findings from the NHANES \& NHIS 2001-2006. BMC Public Health. 2009;9:421.

69. Sanchez-Vaznaugh EV, Kawachi I, Subramanian SV, Sanchez BN, AcevedoGarcia D. Differential effect of birthplace and length of residence on body mass index (BMI) by education, gender and race/ethnicity. Soc Sci Med (1982). 2008;67(8):1300-10.

70. Richmond TK, Thurston I, Sonneville K, Milliren CE, Walls CE, Austin SB. Racial/ethnic differences in accuracy of body mass index reporting in a diverse cohort of young adults. Int J Obes (2005). 2015;39(3):546-8.

71. Diabetes Foundation Norway (Diabetesforbundet). Diabetes type 22019. Available from: https://www.diabetes.no/om-diabetes/diabetes-type-2/. Updated 05.11.19.

72. WHO. Global database on body mass index, vol. 2013; 2013 .

73. Ng Mea. Global, regional, and national levels of maternal mortality, 19902015: a systematic analysis for the Global Burden of Disease Study 2015. Lancet (London, England). 2016;388(10053):1775-812.

\section{Publisher's Note}

Springer Nature remains neutral with regard to jurisdictional claims in published maps and institutional affiliations.

Ready to submit your research? Choose BMC and benefit from:

- fast, convenient online submission

- thorough peer review by experienced researchers in your field

- rapid publication on acceptance

- support for research data, including large and complex data types

- gold Open Access which fosters wider collaboration and increased citations

- maximum visibility for your research: over $100 \mathrm{M}$ website views per year

At BMC, research is always in progress.

Learn more biomedcentral.com/submissions 